की

\title{
CONTRIBUTION OF SUPERVISORS IN IMPROVING TEACHER COMPETENCE at MADRASAH ALIYAH PASAMAN
}

\author{
Israfina, Syaflin Halim, Rahmi \\ Universitas Muhammadiyah Sumatera Barat, Indonesia \\ Israfina005@gmail.com
}

ARTICLE INFO

\section{Article History:}

Received: June 5, 2021

Revised: June 28,2021

Accepted: September

1,2021

Published:October

31,2021

*Corresponding

Author:

Name: Israfina

Email:

israfina005@gmail.com Phone/WA:0812679093

Keyword

\section{ABSTRACT}

Madrasah supervisors have a responsibility in improving the competence of teachers in the institutions they supervise, therefore this research aims to know and analyze how supervisors perform their functions in improving teacher competence in MAN 1 Pasaman. This research is a descriptive research of non-statictic analysis using qualitative methods. Data is obtained through observation, interview and documentation studies. The data collected is then analyzed through three activities, namely data reduction, data presentation, and conclusion drawing. The results prove that: 1) Supervisors play an active role in providing advice and input to madrasah heads for activities to be carried out in order to improve teacher competence, 2) In the activities of improving teacher competence in MAN 1 Pasaman, supervisors act as mediators, facilitators, 3) Teacher competencies in MAN 1 Pasaman are evaluated by supervisors through a review of aspects that become the duties and responsibilities of teachers.

Supervisor Madrasah, improving; teacher competence

\section{Abstrak}

Pengawas Madrasah memiliki tanggungjawab dalam meningkatkan kompetensi guru pada lembaga yang diawasinya, oleh karenanya penelitian ini bertujuan untuk mengetahui dan menganalisis bagaimana pengawas menjalankan fungsinya dalam meningkatkan kompetensi guru di MAN 1 Pasaman. Penelitian ini merupakan penelitian deskriptif analisis non statistic dengan menggunakan metode kualitatif. Data diperoleh melalui observasi, wawancara dan studi dokumentasi. Data yang dikumpulkan kemudian dianalisis melalui tiga kegiatan yaitu reduksi data, penyajian data, dan penarikan kesimpulan. Hasil penelitian membuktikan bahwa: 1) Pengawas berperan aktif dalam memberikan saran dan masukan terhadap kepala madrasah untuk kegiatan yang akan dilakukan dalam rangka peningkatan kompetensi guru, 2) Dalam kegiatan peningkatan kompetensi guru di MAN 1 Pasaman, pengawas berperan sebagai mediator, fasilitator, 3) Kompetensi guru di MAN 1 Pasaman dilakukan evaluasi oleh pengawas melalui peninjauan terhadap aspek-aspek yang menjadi tugas dan tanggungjawab guru.
Kata Kunci
Peran orang tua dan guru, pembelajaran akidah akhlak 


\section{INTRODUCTION}

Madrasah ialah merupakan bagian dari lembaga pendidikan formal yang melaksanakan proses pembelajaran. Dari berbagai literature yang ditemukan, pengelolaan madrasah masih dihadapkan pada berbagai problem (Sartika et al., 2020), pengelolaan madrasah masih jauh dari kata ideal (Hakim et al., 2020). Pada beberapa aspek membutuhkan peningkatan, mulai dari kepala madrasah (Subaidi, 2020), (Maryati, 2016), kompetensi guru (Asmendri et al., 2018), (Tisnelly et al., 2020), fasilitas prasarana serta budaya sekolah yang kurang mendukung (Siswanto \& Hidayati, 2020). Sehingga banyak madrasah swasta yang tutup atau bergabung dengan madrasah yang lain karena dalam persiapan pembagunan yang tidak didasarkan pada perencanaan yang matang.

Peranan guru dalam meningkatkan proses pembelajaran terhadap peningkatan mutu pendidikan di sekolah maupun madrasah sangat penting, untuk pembinaan sumber daya manusia tidak akan terpenuhi jika tidak diawali dari kerjasama yang kuat semua pihak (Suparman et al., 2020). Untuk meningkatkan kualitas dan mutu pendidikan, peningkatan kompetensi para guru adalah suatu keharusan, karena guru merupakan cerminan dari mutu sebuah institusi (Dyment \& O’Connell, 2010), (Biggs \& Tang, 2011). Terkait dengan itu, perhatian yang kuat terhadap guru adalah merupakan bagian yang mesti ditingkatkan oleh semua pihak tanpa terkecuali pengawas yang menjalankan fungsi kepengawasan di madrasah. Saat ini guru di tuntut professional, memiliki kualifikasi akademik yang cukup baik, memiliki kecakapan pribadi agar tercapai apa yang diinginkan oleh lembaga pendidikan sekolah khususnya dan tujuan pendidikan nasional pada umumnya.

Proses pengelolaan pendidikan di lembaga pendidikan akan berjalan dengan baik jika guru yang mengajar menpunyai kualitas yang baik, terlebih guru melakukan pengajaran tentang nilai moral dan agama pada para murid (Yusuf et al., 2020), ini merupakan bekal bagi masa depan anak didiknya, kemudian kulitas guru pada proses belajar sangat dipengaruhi oleh manajemen guru meningkatkan proses pembelajaran terhadap peserta didik.

Di sisi lain, keberadaan pengawas madrasah juga menjadi bagian penting dalam meningkatkan kualitas pendidikan dan kompetensi guru pada lingkungan madarasah tempat dia ditugaskan. Kowalski mengungkapkan bahwa pengawas sebagai bagian dari mitra sekolah mesti menunjukkan kontribusinya dalam memajukan sekolah yang diawasinya (Kowalski, 2006). Pengawas sekolah sesungguhya bukanlah mereka yang melaksanakan fungsi kepengawasan secara murni, melainkan juga membantu sekolah yang diawasi agar lebih cepat dalam mencapai tujuan yang ingin dicapai (Kowalski \& Björk, 2005).

Pengawas sekolah atau madrasah memiliki tanggungjawab dalam mewujudkan kualitas pendidikan serta peningkatannya (Rusiana \& Irwanto, 2017), bahkan lebih tegas diungkapkan oleh Rahmah bahwa kualitas sekolah dapat diukur dari bagaimana keberfungsian dari pengawas yang ada di sana (Rahmah, 2018). Hal ini dapat dimaklumi karena jika pengawas menjalankan fungsinya sebagai supervisor akan dapat membantu peningkatan kompetensi guru (Kuraesin, 2020). Kerjasama yang dibangun antara pimpinan sekolah dengan pengawas akan melahirkan iklim sekolah yang baik untuk semua pihak (Weiss et al., 2014). 
Mengingat begitu pentingnya kompetensi yang mesti dimiliki oleh guru, serta fungsi pengawas dalam meningkatkan kualitas pendidikan, maka peneliti tertarik untuk mengkaji aspek yang belum diungkap oleh para peneliti terdahulu, yakni bagaimana kontribusi yang diberikan oleh pengawas dalam meningkatkan kompetensi guru?, oleh karenanya peneliti akan mendalami aspek ini untuk mengetahui peran aktif yang dilakukan pengawas dalam melahirkan guru yang berkualitas dan berkompeten.

\section{METHOD}

Penelitian ini dilakukan di Madrasah Aliyah Negeri 1 Pasaman, lembaga ini dipilih sebagai tempat penelitian ialah dikarenakan madrasah ini sebagai tempat pendidikan yang selalu menjadi pilihan utama bagi para calon peserta didik dalam melanjutkan pendidikan mereka ke jenjang Aliyah. Oleh karenanya kualitasnya mesti selalu ditingkatkan sesuai dengan kebutuhan zaman. Waktu penelitian ini dilakukan ialah selama enam bulan, yakni sejak Agustus 2020 sampai Januari 2021.

Penelitian ini menggunakan pendekatan kualitatif, keterpilihan kualitatif sebagai pendekatan yang digunakan ialah disebabkan tipikal data yang akan diteliti berupa data naturalistic yang berbentuk kata, kalimat yang didapatkan dari sumber penelitian. Seiring dengan itu, sumber penelitian ini ialah kepala madrasah, guru yang bertugas di madrasah 1 Pasaman dan pengawas. Posisi kepala madrasah dijadikan sebagai informan penelitian disebabkan dia memiliki pengetahuan yang cukup terkait konten dan data yang dibutuhkan dalam penelitian ini. Sementara guru yang ada di MAN 1 Pasaman dijadikan sebagai informan ialah karena mereka mengalami langsung terkait data yang dibutuhkan, adapun posisi pengawas dijadikan sebagai sumber penelitian ialah untuk mengkonfirmasi data yang didapatkan dari informan sebelum diinterpretasikan.

Untuk mengumpulkan data dari informan yang disebutkan di atas, serta realita yang ada di lapangan, peneliti menggunakan teknik observasi, wawancara dan studi dokumentasi. Observasi yang digunakan dalam penelitian ini ialah jenis observasi non partisifan, jenis observasi ini dipandang tepat karena mengingat keterbatasan waktu peneliti serta waktu dari objek yang diteliti hadir ke madrasah. Adapun bentuk wawancara yang dipilih dalam penelitian ini ialah wawancara tidak terstruktur, dimana peneliti tidak menyusun kisi-kisi pertanyaan secara detail, melainkan menanyakan secara spontan terkait apa yang dipikirkan dan dirasakan kepada informan. Studi dokumentasi berguna untuk mengetahui tentang informasi, kebijakan yang didakan di MAN 1 terkait peran pengawas dalam meningkatkan kompetensi guru.

Semua data yang didapatkan, baik melalui observasi, wawancara maupun studi dokumentasi kemudian dianalisis secara interaktif. Peneliti melakukan analisis terhadap semua data yang didapatkan sejak pengumpulan data, klasifikasi data, interpretasi sampai pada tahap penarikan kesimpulan, semuanya dilakukan berjalan seiring. Oleh karenanya, validitas data penelitian ini akan dapat diukur melalui kekuatan trangulasi.

\section{RESULTS\&DISCUSSION}

Madrasah Aliyah Negeri 1 Pasaman merupakan bagian dari lembaga pendidikan yang ada di Pasaman dan berkontribusi besar dalam memajukan pendidikan di Kabupaten Pasaman. Terkait dengan itu, di MAN ini ditugaskan salah seorang pengawas 
yang diharapkan mampu menjadi mediator, fasilitator sekaligus evaluator dalam keberlangsungan penyelenggaraan pendidikan. Untuk itu, sesuai dengan tujuan penelitian yang dijelaskan sebelumnya, berikut ini akan diuraikan deskripsi serta hasil analisis terhadap data yang terkait dengan konten penelitian.

\section{Perencanaan Peran Pengawas dalam Meningkatkan Kompetensi Kepribadian, Pedagogik dan Profesional Guru}

Pada dasarnya yang membedakan hubungan antara pengawas dan pendidik adalah pembinaan. Selaku wujud pertanggungung jawaban pengawas membagikan pembinaan serta pembimbingan terhadap pendidik yang terus menerus hingga pendidik berkembang serta tumbuh jadi pendidik yang handal. Bila pendidik di Madrasah binaannya seluruhnya handal, sehingga kualitas pembelajaran di Madrasah itu pula bertambah. Kualitas pembelajaran yang bertambah di Madrasah binaan ialah indikator bahwa pengawas yang bertugas pada madrasah tersebut telah sukses dalam menjalankan fungsinya sebagai pengawas (Ansar, 2015).

Setiap melakukan perkerjaan pokok, pengawas Madrasah melakukan kewajiban dari supervisi, mulai dari ataupun supervisi manajerial. merupakan kegiatan supervisi yang berkaitan kegiatannya dengan keahlian guru proses peningkatan kualitas pendidikan serta tutorial di Madrasah.

Kompetensi pedagogk merupakan Keahlian mencerna pendidikan partisipan didik, perencanaan serta penerapan pendidikan, penilaian partisipan didik buat mengaktualisasikan bermacam kemampuan yang dimilikinya. Kompetensi pendidikank ialah keahlian yang harus di miliki guru dalam proses belajar pendidikan siswa.

Observasi yang penulis jalani di MAN 1 Pasaman, penulis memandang tahapan tahapan penerapan supervisi akademik serta tahapan tahapan supervisi Manajerial yang dicoba terlebih dulu menbuat agenda aktivitas supervsisi akademik didata pengajar pengajar yang akan disupervsisi,mengadakan rapat dan koordinasi dulu dipihak internal Madrasah.

Pengawas selaku partner guru dalam melakukan kegiatan supervisi akademik sangat berarti. melaksanakan, ataupun apalagi melakukan kewajibanya pengawas berfungsi aktif berusaha meyampaikan data secara valid. Pengawas selaku rekan ditunjukkan oleh indikator perilaku pengawas yang bisa dipercaya, Sopan, menyanjung buat memotivasi guru, serta menyanjung buat membuat lebih percaya diri. Pengawas dalam menjalankan fungsi kepengawasannya di madrasah senantiasa berkomunikasi dengan kepala madrasah dan para wakil yang ada di sana.

Sebagaimana wawancara penulis dengan bapak pengawas yang mengatakan bahwa: "tahapan-tahapan penerapan supervisi akademik serta supervisi Manajerial di MAN 1 Pasaman terlebih dulu pihak Madrasah mendata pendidik yang hendak disupervsisi, sebab kebutuhan dari pada guru pasti pihak intern Madrasah yang lebih mengenali, sebab kepala Madrasah selalu dan berinteraksi bersama guru. Sehabis itu pihak madrasah mengkoordinasikan kepada pengawas Madrasah". Hasil wawancara ini membuktikan kekuatan koordinasi antara pengawas dan kepala madrasah di MAN 1 terjalin kuat. Langkah ini merupakan dasar untuk mensukseskan tugas seorang pengawas. Hasil temuan ini selaras dengan yang diungkapkan Madonia yang menegaskan bahwa kekuatan supervisor lembga pendidikan terlihat dari bagaimana dia membangun kerjasama dengan pihak sekolah (Madonia, 1983).

Selanjutnya penulis melakukan wawancara dengan guru MAN 1 Pasaman, dia mengungkapkan bahwa :"tahapan-tahapan dalam penerapan supervisi akademik serta 
supervisi Manajerial yang dicoba terlebih dulu menyusun agenda aktivitas supervsi". Pendapat lain juga diungkapkan oleh Informan lain bahwa "Saya diberitahu jadwal supervsisi akan dilaksanakan. Kemudian menyiapkan perangkat pembelajaran dan selanjutnya pengawas terjun ke lapangan melakukan supervsisi, kunjungan kelas atau supervsisi administrasi”.

Selanjutnya penulis melakukan wawancara dengan Kepala MAN 1 Pasaman yang untuk memperkuat wawancara penulis dengan pengawas dan guru mengungkapkan bahwa : "Langkah yang dilakukan yaitu terlebih dahulu sebelum dilakukan supervisi akademik berkoordinasi di MAN 1 Pasaman yaitu pihak Madrasah menyususn jadwal kegiatan supervsisi akademik, mendata pendidik akan disupervsisi, kemudian pihak madrasah mengkoordinasikan kepada pengawas Madrasah dan pengawas terjun ke lapangan Melakukan supervsisi kunjungan kelas dan supervisi administrasi, selanjutnya pengawas melaksanakan tugasnya di madrasah.

Supervisi akademik ialah serangkaian aktivitas menolong guru meningkatkan kemampuannya mengelola proses pendidikan. Evaluasi unjuk tugas guru dalam kegiatan pendidikan, melalui supervisi akademis ini guru akan medapatkan informasi dari supervisor terkait dengan kemampuan akademisnya. Untuk itu, kegiatan ini ialah bagian yang terkait dari seluruh aktivitas supervisi akademik. Sesuai wawancara penulis dengan pengawas madrasah mengungkapkan bahwa: "supervisi akademik dan supervisi manajerial madrasah adalah dua hal yang secara berkesinambungan dilaksanakan di MAN 1 Pasaman".

Penulis melakukan observasi di MAN 1 Pasaman pada senin tanggal 9 November 2020 penulis melihat bahwa tahapan-tahapan yang diterapkan pengawas dalam melakukan supervisi akademik serta supervisi Manajerial ialah dengan memulai penyusunan agenda yang akan dilakukan di madrasah, pengawas terlebih dahulu mengadakan rapat bersama kepala madrasah dan semua wakil kepala. Pembahasna ini hanya melibatkan team supervisor madrasah, setelah itu melaksanakan koordinasi dengan pengawas madrasah serta pengawas terjun kelapangan.

Selanjutnya penulis melakukan wawancara kepada guru MAN 1 Pasaman mengungkapkan bahwa : "Supervisi akademik dilakukan satu kali dalam satu semester sedangkan supervsisi manajerial dilakukan di awal tahun pelajaran baru". Setelah melakukan wawancara dengan pengawas kemudian penulis melakukan wawancara dengan kepada Madrasah untuk memperkuat hasil wawancara dengan pengawas dan guru MAN 1 Pasaman mengungkapkan bahwa: "dilakukan sedangkan supervisi manajerial dilakukan diawal tahun pelajaran baru dan pengawas madrasah selalu memantau perkembangan madrasah".

Dari beberapa wawancara penulis di atas diperkuat oleh Kepala Madrasah yang mengungkapkan bahwa pengawas selalu memantau perkembangan madrasah melalui supervisi akademik, kegiatan ini dilakukan oleh pengawas yaitu sekali dalam satu semester sedangkan supervisi manajerial dilakukan diawal tahun pelajaran baru.

Bekaitan dengan data yang didapatkan dketahui bahwa pengawas di MAN 1 memberikan motivasi serta dorongan untuk pendidik agar selalu belajar mencari teori baru yang berhungan dengan apa mereka terangkan serta ataupun metode yang pas untuk mengajarkannya. Sesuai dengan yang diungkapkan pengawas dia mengatakan bahwa, guru di era sekarag ini mesti meningkatkan kemampuan mereka dalam menyampaikan materi pembelajaran, karena era revolusi industri jangan sampai membuat guru tidak mampu untuk menggunakan media yang bersifat teknologi. Hasil penelitian ini juga sejalan dengan pandangan Ritonga dan kawan-kawan yang menegaskan bahwa 
kemampuan dan ketrampilan memanfaatkan dan menggunakan media dan metode terbaru adalah tuntuan bagi setia guru (Ritonga et al., 2016; Ritonga et al., 2020; Sartika, Desriwita, et al., 2020).

Sebagai seorang motivator, pengawas madrasah senantiasa memberikan inspirasi kepada guru-guru di MAN 1 Pasaman. Pengawas memiliki cara sendiri yang pas buat meningkatkan motivasi para guru. Informan yang penulis wawancarai mengungkapkan bahwa : "Dalam setiap kesempatan, pengawas menyampaikan berbagai bentuk reward yang akan didapatkan oleh guru ketika mereka memiliki prestasi". Pada waktu yang berbeda, kepala MAN 1 Pasaman juga menyatakan "pihak madrasah akan selalu mendukung setiap kegiatan yang direncanakan pengawas dalam upaya peningkatan kompetensi guru di lingkungan madrasah Aliyah Negeri 1 Pasaman. Hal ini dikarenakan pendidik di berbagai tempat tanpa terkecuali di MAN 1 Pasaman terkadang mesti diberikan motivasi yang cukup. Beban tugas guru yang berat adakalanya membuat pendidik merasakan penurunan semangat. Setelah itu memberikan semangat agar melanjutkan pendidikan ke jenjang yang lebih tinggi, atau memakai bentuk bentuk baru dalam proses pendidikan supaya pendidikan dikelas tidak itu itu saja"

Pendapat lain juga diungkapkan oleh guru bahwa: "semangat yang diberikan pengawas sangat saya perlukan, karena beliau adalah pejabat atasan kami yang memiliki kewenangan dalam dalam menberikan pembinaan bimbingan kepada kami dalam bertugas. Beliau Dia kerap berikan motivasi kepada kami untuk selalu bertugas selalaku pendidik di sekolah secara profesional, setiap saat tetap profesional, walaupun tidak adanya pengawas, meski tidak ada disupervisi administrasi. Pengawas memberikan semangat kepada kami kami kalau fitur pendidikan pembelajaran disiapkan tidak saja ketika akan disupervisi. Tapi perangkat disiapkan setiap ketika dalam pembelajaran"

\section{Pelaksanaan Peran Pengawas dalam Meningkatkan Kompetensi Kepribadian, Paedagogik Dan Profesional Guru}

Pengawas di MAN 1 Pasaman melaksanakan tugas kepengawasan dalam meningkatkan kompetensi guru. Dalam aspek kompetensi kepribadian, langkah yang dilakukan oleh pengawas di MAN 1 sebagaimana disampaikan oleh informan ialah pengawasan terhadap bagaimana guru bertingkah, bertutur kata, serta berpakaian. Dari data yang ditemukan diketahui bahwa pengawas di MAN 1 Pasaman selalu menyampaikan bahwa prilaku seorang guru menjadi panutan bagi semua lapisan masyarakat, baik itu masyarakat secara luas terutama peserta didik.

Informan lain menyampaikan bahwa tutur kata setiap guru di MAN 1 Pasaman menjadi aspek yang disoroti dan diperhatikan oleh pengawas, karena menurutnya seorang pendidik tidak hanya melakukan tugas sebagai guru di dalam kelas, melainkan juga mesti mendidik di luar kelas.

Ada pula aktivitas yang dicoba dalam penerapan pengawasan merupakan Membangkitkan serta memicu semangat Pendidik serta para pegawai Madrasah yang lain dalam melakukan tugas tiap - tiap dengan sebaik - baiknya , Berupaya mengadakan serta memenuhi alat-alat peralatan tercantum macam-macam media yang dibutuhkan untuk kelancaran proses pembelajaran yang baik, dengan guru berupaya meningkatkan, mencari serta memakai teknik terbaru dalam kegiatan belajar mengajar. Membina kerjasama yang baik serta harmonis antara guru, murid serta pegawai Madrasah yang lain; serta berupaya mengeksplor kualitas serta ilmu dari para guru-guru serta pegawai Madrasah. 
Sebagaimana wawancara penulis dengan pengawas Madrasah tentang strategi Strategi supervsisi akademik dan manajerial dalam mensupervisi di MAN 1 Pasaman, pengawas Madrasah mengungkapkan bahwa: "mensosialisasikan metode, media serta teknik pembelajaran yang baru bagian dari langkah yang dilakukan oleh pengawas dalam meningkatkan kompetensi guru. Teknik yang sering diakukan oleh pengawas Madrasah adalah kunjungan kelas.

Pengawas merupakan partner / mitra guru dalam tingkatkan kualitas proses serta hasil pendidikan serta tutorial di Madrasah binaannya . Antara pendidik serta pengawas berkolaborasi sebab silih memerlukan ataupun silih memenuhi. Dengan konsep pengawas selaku mitra / partner melakuka kerjasama yang dicoba antara pendidik serta pengawas perdasarkan pada kesejajaran peran ataupun memiliki derajat yang sama antara kedua belah pihak. Ini berarti ikatan antara pengawas serta pendidik dicoba merupakan ikatan yang setara, tidak terdapat yang silih mengeksploitasi satu sama lain serta timbul rasa silih memerlukan antara kedua belah pihak.

Dalam rangka melaksanakan kedudukan serta gunanya selaku inovator, pengawas wajib mempunyai strategi yang pas buat menjalakan ikatan yang harmonis dengan area mencari gagasan baru, mengintegrasikan setiap aktivitas, membagikan kepada segala tenaga kependidika di Madrasah, serta meningkatkan model-model pendidikan yang inovatif.

Wawancara penulis di atas diperkuat oleh wawancara dengan kepala Madrasah mengungkapkan bahwa Pengawas selaku inovator serta pelopor dalam meningkatkan inovasi pendidikan serta tutorial di sekolah binaannya. Inovator merupakan orang bawa ilham, gagasan, tata cara, ataupun suatu yang baru untuk sekelompok orang . Dengan sistem pembelajaran saat ini desentralisasi pengelolaan Madrasah dikala ini merupakan penerapan dengan sistem Manajemen Berbasis Madrasah .

Pengawas Madrasah wajib mempunyai power selaku inovator, sebab pengawas yang mempunyai keahlian konseptual tetap menciptakan metode ataupun trik yang bisa digunakan buat memajukan madrasah binaannya. Sehingga, pengawas bisa merancang, merumuskan ide-ide brilian sehingga madrasah yang dibinaannya dalam perkembangannya tetap menciptakan inovasi-inovasi baru yang tidak saja berguna untuk pertumbuhan Madrasahnya, namun pula dapat ditiru Madrasah lain yang bukan bagian dari binaan pengawas yang menjalankan tugas, sehingga kualitas pembelajaran di tanah air ini bertambah.

Dalam rangka melaksanakan kedudukan serta gunanya selaku inovator, pengawas wajib mempunyai strategi yang pas buat menjalakan ikatan yang harmonis dengan area mencari ide ide baru, mengabungkan tiap aktivitas, membagikan kepada segala tenaga kependidikan di Madrasah, serta meningkatkan model-model pendidikan yang inovatif. Sejalan dengan wawancara penulis bersama pengawas Madrasah yang mengungkapkan: "Pembinaan pendidikan dilakukan terus menerus dan sesuai dengan kebutuhan.

Evaluasi peran pengawas dalam meningkatkan kompetensi kepribadian, paedagogik dan profesional guru adalah dengan mengadakan evaluasi terhadap administrasi, kelengkapan administrasi guru. Pengawas dalam menilai profesional pendidik di MAN 1 Pasaman adalah dengan melakukan supervisi administrative. Pengawas datang mengadakan evaluasi terhadap kelengkapan administrasi guru dan memotivasi guru agar selalu semangat dalam mengajar, selalu disiplinan sehingga dengan adanya motivasi yang diberikan kepada guru bisa melahirkan pembelajaran lebih baik untuk kedepannya.

Hendaknya sebagai pengawas yang mempunyai wewenang dalam peningkatan mutu madrasah dalam hal akademik pendidik dan manajemen madrasah diharapkan lebih aktif 
lagi dalam memajukan lembaganya menjadi lebih baik lagi. Peran pengawas perlu ditingkatkan, sehingga pendidik lebih maksimal.

Hendaknya seorang guru tetap berusaha meningkatkan perencanaan dalam meningkatkan proses pembelajaran terhadap mutu pendidikan agar dalam pemberian materi siswa selalau serius dalam mengikuti pelajaran dan merasa tertarik dengan pelajaran untuk itu seharusnya guru memiliki kemampuan dalam mengelola kelasnya dan bisa menggunakan berbagai macam metode yang bervariasi sesuai dengan keadaan kelas serta merubahnya apabila metode sebelumnya kurang tepat.

\section{CONCLUSIONS}

Temuan penelitian di atas membuktikan bahwa pegawas yang bertugas di Madrasah Aliyah Negeri 1 Pasaman memiliki kontribusi dalam meningkatkan kompetensi guru-guru yang mengajar di MAN 1 tersebut. Perencanaan pengawasan di MAN 1 Pasaman dilakukan dengan menyusun perencanaan dengan melakukan koordinasi bersama kepala Madrasah tentang bagaimana serta kapan pelaksanaan pengawasan dilakukan. Adapun dalam pelaksanaan tugas pengawas di MAN 1 Pasaman dilakukan sesuai dengan yang telah direncanakan. Dari tugas kepengawasan yang telah dilaksanakan di MAN 1 Pasaman terlihat dapat meningkatkan kompetensi guru-guru.

\section{BIBILIOGRAPHY}

Ansar. (2015). Measuring the Performance of School Superintendent. Journal of Education and Practice, 6(2), 103-109.

Asmendri, A., Marsidin, S., Rusdinal, R., \& Mukhaiyar, M. (2018). An Analysis of Managerial Competence of the Madrasah Principals in Islamic Senior High School in Tanah Datar. Al-Ta Lim Journal, 25(1), 56-70. https://doi.org/10.15548/jt.v25i1.350

Biggs, J., \& Tang, C. (2011). Teaching for quality learning at university. In Innovations in Education and Teaching International (Vol. 50, Issue 4). British Library. https://doi.org/10.1080/14703297.2013.839332

Dyment, J. E., \& O'Connell, T. S. (2010). The quality of reflection in student journals: A review of limiting and enabling factors. Innovative Higher Education, 35(4), 233-244. https://doi.org/10.1007/s10755-010-9143-y

Hakim, R., Khadijah, Ritonga, M., Susanti, W., \& Rahmi. (2020). Institute Quality Improvement Through Management Training of Accreditation Preparation in TK Aisyiyah Bustanul Athfal Padang. Proceedings of the International Conference of Early Childhood Education (ICECE 2019) Institute, 44(Icece 2019), 55-65. https://doi.org/10.2991/assehr.k.200715.012 
Kowalski, T. J. (2006). The school superintendent: Theory, practice, and cases. In Educational Leadership Faculty Publications. Paper 50. https://doi.org/10.4135/9781452204451

Kowalski, T. J., \& Björk, L. G. (2005). Role expectations of the district superintendent: Implications for deregulating preparation and licensing. Journal of Thought, 40(2), 73-118.

Kuraesin, E. (2020). Peran Pengawas dalam Meningkatkan Kemampuan Profesional Guru. Indonesian Journal of Education Management and Administration Review, 4(1), 171-178.

Madonia, R. J. (1983). Loyola eCommons The Analysis of the Relationship of the Superintendent's Satisfaction with the Principal's Leadership Behavior and the Organizational Climate [Loyola University Chicago]. https://ecommons.luc.edu/luc_diss/2483

Maryati. (2016). Pola Kepemimpinan Kepala Madrasah dalam Meningkatkan Mutu Pendidikan di MTs Nurul Qur'an Tegalweropucakwangi Pati. Quality, 4(1), 163181.

Rahmah, S. (2018). Pengawas Sekolah Penentu Kualitas Pendidikan. Jurnal Tarbiyah, 25(2), 174-193. https://doi.org/10.30829/tar.v25i2.378

Ritonga, M., Nazir, A., \& Wahyuni, S. (2016). Pembelajaran Bahasa Arab Berbasis Teknologi Informasi dan Komunikasi. Arabiyat: Jurnal Pendidikan Bahasa Arab Dan Kebahasaaraban, 3(1), 1-12. https://doi.org/http://dx.doi.org/10.15408/a.v3i1.2879

Ritonga, M., Nazir, A., \& Wahyuni, S. (2020). Pengembangan Model Pembelajaran Bahasa Arab Berbasis Teknologi Informasi \& Komunikasi dalam dialektika Revolusi Industri 4.0 [Development of Arabic language learning Model based on information Technology \& Communication in dialectic Industrial Revolution (Bambang, I. Naska, \& F. Alrasi (eds.); Januari). Deepublish.

Rusiana, \& Irwanto. (2017). Peranan Pengawas Dalam Meningkatkan Mutu Pendidikan Pada Sekolah Dasar Negeri di Kecamatan Bataguh Kabupaten Kapuas. ADMINISTRAUS - Jurnal Ilmu Administrasi Dan Manajemen, 3(3), 27-56. http://ejournal.stiabinabanuabjm.ac.id/index.php/administraus

Sartika, F., Desriwita, E., \& Ritonga, M. (2020). Pemanfaatan Media Pembelajaran Dalam Meningkatkan Kualitas Pembelajaran PAI di Sekolah. Humanika, Kajian Ilmiah Mata Kuliah Umum, 20(2), 115-128. https://doi.org/10.21831/hum.v20i2.32598

Sartika, F., Ritonga, M., \& Rasyid, A. (2020). Implementation of Islamic Religious Education in Madrasah Ibtidaiyah During Covid-19 Pandemic. Khalifa: Journal of Islamic Education, 4(2), 97-117. 
Siswanto, E., \& Hidayati, D. (2020). Management Indicators of Good Infrastructure Facilities To Improve School Quality. International Journal of Educational Management and Innovation, 1(1), 69-81. https://doi.org/10.12928/ijemi.v1i1.1516

Subaidi, S. (2020). Kepemimpinan Kepala Madrasah Dalam Upaya Meningkatkan Mutu Pendidikan Dan Kinerja Guru di MAN 1 Pati. Tadbir : Jurnal Studi Manajemen Pendidikan, 4(2), 161-174. https://doi.org/10.29240/jsmp.v4i2.1428

Suparman, Untoro, I. H. T., Suwadi, Prabowo, A., Andriyani, Humanika, E. S., Hairun, Y., \& Ritonga, M. (2020). The Implementation of Community Partnership Program to Improve the Quality of Online Learning during the Covid-19 Pandemic. Universal Journal of Educational Research, 8(11 B), 6134-6138.

https://doi.org/10.13189/ujer.2020.082249

Tisnelly, Ritonga, M., \& Rasyid, A. (2020). The Competency of Islamic Education Teachers in Madrasah Ibtidaiyah 1 West Pasaman After Certification. Ruhama: Islamic Education Journal, 3(1), 45-56.

Weiss, G., Templeton, N., Thompson, R., \& Tremont, J. (2014). Superintendent and School Board Relations: Impacting Achievement through Collaborative Understanding of Roles and Responsibilities. School Leadership Review, 9(2), 4.

Yusuf, M., Ritonga, M., \& Mursal. (2020). Implementasi Karakter Disiplin dalam Kurikulum 2013 Pada Bidang Studi PAI di SMA Islam Terpadu Darul Hikmah. Jurnal Tarbiyatuna, 11(1), 49-60. 